\title{
Application of IPFC Scheme in Power System Transients and Analysed using Fuzzy Technology
}

\author{
G.Radhakrishnan \\ Assistant Professor- Electrical Engineering. \\ RVS College of Engineering and Technology, \\ Coimbatore, \\ Tamilnadu, India.
}

\author{
M.Rathika \\ Assistant professor- Electrical Engineering. \\ Sardar Raja College of Engineering - \\ Alangulam \\ Tamilnadu, India.
}

\begin{abstract}
The widespread use of power electronics in the field of power systems has grown significantly. With the growth of technology, power systems are seeking new and efficient forms of controlling power [1]. This paper deals with the development of Interline Power Flow Controller (IPFC) using fuzzy technology, suitable for an independent controllability over each compensated line in a multiline power system. The analysis developed is based on the $\mathrm{d}-\mathrm{q}$ orthogonal coordinates, which shows an appropriate and easy method for assessing the IPFC response towards the system's operation. In the proposed scheme, series and shunt configuration employing an interline power flow controller using fuzzy technology is designed. Most of the compensation is provided by series controller. In case of excess real power demand shunt controller is used. The simulation is done using Matlab software-Simulink.
\end{abstract}

Keywords: Flexible AC Transmission System, Static Synchronous Series Compensator, Unified Power Flow Controller, Interline Power Flow Controller, Generalized Interline Power Flow Controller, Voltage Source Converter, and Voltage Source Inverter

\section{INTRODUCTION}

In the vicinity, now a days, the subject of power electronics has had a great impact on the field of electric power system. The development of the thyristors has resulted in the rise of new breed of thyristor based fast operating devices for control and switching operations. Flexible AC Transmission System (FACTS) devices are new comings, which have found a wide spread application in the power industry for active and reactive power control.

Commonly, power systems present an inadequate line flow control which may result in overloaded lines. Sometimes the neighbouring lines could be operating as an idle state line. Hence there should be a better control of the power flow and an increased amount of flexibility. Recently, some new devices have been put forward within the FACTS technology, namely:

Controller)

-Static Synchronous Compensator (STATCOM), -Static Synchronous Series Compensator (SSSC) -Unified Power Flow Controller (UPFC) -IPFC (Interline Power Flow Controller) and -GIPFC (Generalized Interline Power Flow To obtain an independent controllability over each transmission line of a multiline system, IPFC and GIPFC are used. With the cost (of the high power semiconductors and converters) declining steadily, both the GIPFC and the IPFC arrive as a stand out solution, instead of using individually controlled UPFCs (Unified Power Flow Controller) for the power flow control of multi-line systems.

In the proposed thesis an interline power flow controller is developed using fuzzy technology and the steady state response of the controller is analyzed by simulation results.

\section{IPFC CONFIGURATION}

The IPFC steady-state operation needs the sum of the active power, exchanged by the total number of converters, to be zero. Under certain conditions such as when voltage support in the substation bus is not required, the shunt converter can be dispensed with and instead the IPFC constituted by SSSCs can be connected to each other through a common DC capacitor. In this case, the real power required for varying the angular position of the series voltages, will have to be supplied from one of the AC systems [2].

In the IPFC configuration, the series voltage being injected into each line can be controlled in both its magnitude $\left(0 \leq V p q \_n \leq V p q \_n \max \right)$ and phase angle $\left(0 \leq \theta p q \_n \leq 360^{\circ}\right)$. thus it can be decomposed into a quadrature and an in-phase voltage component.

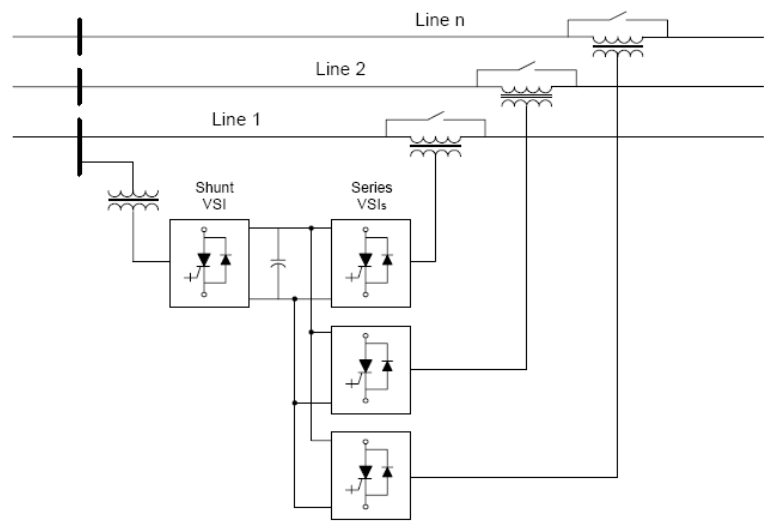

Figure 1.IPFC basic configurations for multi-line power flow control

The quadrature voltage injection, with respect to the line current, has predominant effect on the real power flow. The In-phase voltage injection has predominant effect on the line's reactive power flow and it is associated to the real power exchange taking place between the converters. The subscript $n$, in these voltage and angle ranges, refers to any of the series converters present in the whole system. 


\section{IPFC MODEL AND ANALYSIS}

The analysis developed in this section considers an IPFC connected to two balanced independent AC systems (Fig. 2). If the buses $V 11$ and $V 21$ are merged to have more than two compensated lines, then the scheme would reflect the case of a multi-line substation from which power is dispatched to different receiving-ends. For analysis, the equivalent sending and receiving end sources in both systems are regarded as stiff AC sources (infinite buses). Also, it is assumed that Systems 1 and 2 have identical line parameters. Under the IPFC configuration $(P s h=0, Q s h=0)$, System 2 will be termed as a secondary system, as it will have to provide the series real power demanded by the primary system. For the case of a classical IPFC scheme, the real power exchange of converter2 is pre-defined (i.e. there exists a constraint for line2) and therefore, only its series reactive compensation controls the power flow in this line [3].

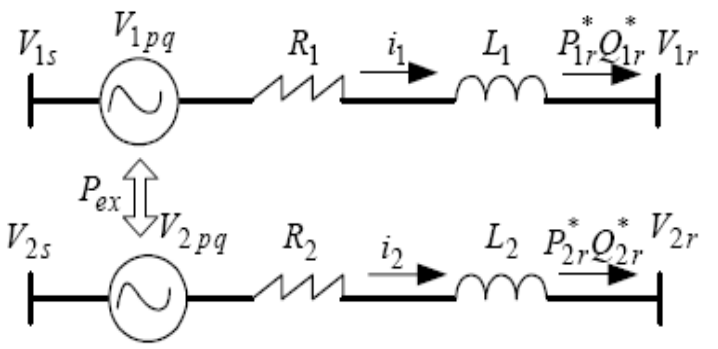

Figure 2. Elementary IPFC scheme used in the analysis

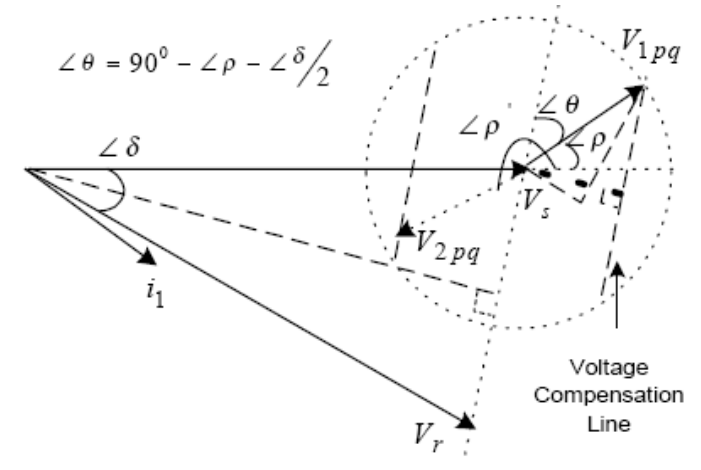

Figure 3.Vector diagram

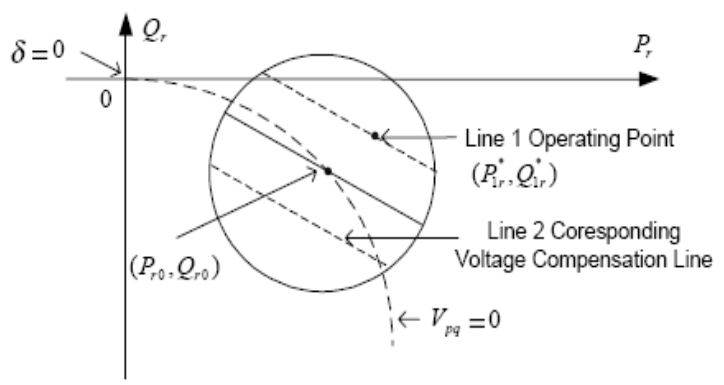

Figure 4.Control area

Line current flowing through series coupled transformer will cause power exchange with inverter. As we know, the active power exchange between two lines can be approximated as follows:
(1)

$$
\begin{aligned}
P_{e x}= & \left(\left(V \cdot V_{1} p q\right) / X\right)[\sin (\delta+\rho)-\sin \rho] \\
= & ((2 V \cdot \sin (\delta / 2)) / X) \cdot V_{1} p q \cdot \cos ((\delta / 2)+\rho)
\end{aligned}
$$

where $\mathrm{X}=\omega L$.

From the above equation, it can be easily seen that the power exchange is not changed if the last item is kept constant. A voltage compensation line which is parallel with the line of vector $V s-V r$ in Fig. 3 can be defined as in [4,5]. Whenever the operating point lies in that line, the active power demand of line 1 remains unchanged. Hence, to maintain the DC link voltage, it is compulsory for line 2 to provide equal amount of active power. Thus, the operating point of line 2 must lie in the corresponding voltage compensation line in the opposite side whose position can be determined by the length of the perpendicular line with the compensation line in Fig. 3. To determine the particular operating point of line 2, it leaves us another free control degree: active or reactive power which is easy to be seen from Fig. 3 and Fig. 4.

Interestingly, if $V 2 p q=V 1 p q$, then to maintain the DC link voltage, the phasor relationship of the injected voltage must meet:

as seen in fig. 3 .

$$
\begin{gathered}
\angle \rho=180^{\circ}+\rho \\
\quad \text { (or) } \\
\angle \rho=180^{\circ}-\delta-\rho
\end{gathered}
$$

$$
\begin{aligned}
& \text { If } \mathrm{V}_{2} \mathrm{pq}=\mathrm{V}_{1} \mathrm{pq}=\mathrm{Vpq} \\
& \text { and } \\
& \angle \rho=180^{\circ}+\rho \text {, then } \\
& \mathrm{P}_{1} \mathrm{~s}+\mathrm{P}_{2} \mathrm{~s}=2\left(\mathrm{~V}^{2} \square \mathrm{X}\right) \cdot \sin \delta+((\mathrm{V} . \mathrm{Vpq}) \square \mathrm{X}) .(\sin \rho+\sin \angle \rho) \\
& =2\left(\mathrm{~V}^{2} \square \mathrm{X}\right) \cdot \sin \delta
\end{aligned}
$$$$
\text { (2) }
$$

$$
\begin{aligned}
\mathrm{Q}_{1} \mathrm{~s}+\mathrm{Q}_{2} \mathrm{~S} & =2\left(\mathrm{~V}^{2} \square \mathrm{X}\right) \cdot(\cos \delta-1)+((\mathrm{V} \cdot \mathrm{Vpq}) / \mathrm{X}) \cdot(\cos \rho+\cos \angle \rho) \\
& =2\left(\mathrm{~V}^{2} / \mathrm{X}\right) \cdot(\cos \delta-1)
\end{aligned}
$$$$
\text { (3) }
$$$$
\begin{gathered}
\mathrm{P}_{1} \mathrm{r}+\mathrm{P}_{2} \mathrm{r}=2\left(\mathrm{~V}^{2} \square \mathrm{X}\right) \cdot \sin \delta \\
+((\mathrm{V} \cdot \mathrm{Vpq}) / \mathrm{X}) \cdot(\sin (\delta+\rho)+\sin (\delta \\
+\angle \rho))
\end{gathered}
$$$$
=2\left(\mathrm{~V}^{2} / \mathrm{X}\right) \cdot \sin \delta
$$$$
\text { (4) }
$$$$
\mathrm{Q}_{1} \mathrm{r}+\mathrm{Q}_{2} \mathrm{r}=2\left(\mathrm{~V}^{2} / \mathrm{X}\right) \cdot(\cos \delta-1)+((\mathrm{V} \cdot \mathrm{Vpq}) / \mathrm{X}) .
$$$$
(\cos (\delta+\rho)+\cos (\delta+\angle \rho))
$$$$
=2\left(\mathrm{~V}^{2} / \mathrm{X}\right) \cdot(\cos \delta-1)
$$

(5)

\section{Remarks:}

- Under the condition $\mathrm{V}_{2 \mathrm{pq}}=\mathrm{V}_{1 \mathrm{pq}}$ and $\rho^{\prime}=180^{\circ}+\rho$ total active and reactive power from the sources and the total active and reactive power to the sinks remain the same as what they were before IPFC regulation;

- For a more special condition, $\rho=0^{\circ}, \rho^{\prime}=180^{\circ}$ or $\rho=180^{\circ}$, $\rho^{\prime}=0^{\circ}$ the active powers from the sources of both lines remain constant while redistributed in the sinks via the common DC link after IPFC regulation by amount of (V .Vpq $\sin \delta) / X$. The following two sections will discuss control methods for the IPFC. Line 1 is assumed as primary line without loss of generality and reference inputs are receiving end active and reactive power of line 1 , receiving end active or reactive power of line 2. VSC model and decoupled PI control proposed in [6] are selected. Decoupled PI control can be directly applied to control the assumed primary line 1 [6]. Thus the main issue is how to determine the reference currents 
for line 2 with the reference inputs, while maintaining the DC link voltage. Then decoupled PI control can also be applied to control line 2 to follow the derived reference currents.

\section{IPFC OVERALL CONTROL SYSTEM}

The control system of the IPFC analyzed and simulation of the system uses fuzzy controllers. The output of the AC voltage controller relating $V 22$ is the quadrature component of $I s h$, and the output of the DC voltage controller is the in-phase component of Ish. The $d, q$ components of $V s h$ and its phase angle $(\theta s h)$, obtained from the shunt current controller, are then used in the shunt converter switching logic [4].

Through the series converters (VSI-1, VSI-2), it can controlled either the power flow or the series voltage injected. In the series control system used, the $\Delta P$ and $\Delta Q$ errors are utilized by the fuzzy controllers to compute the $V q$ and $V d$ components of the series voltage (Fig. 5 b) and its series angle, which will then be used in the series converter switching logic. The control diagram of the GIPFC secondary system (System 2) will essentially be similar to that illustrated in Fig. 5 (b).

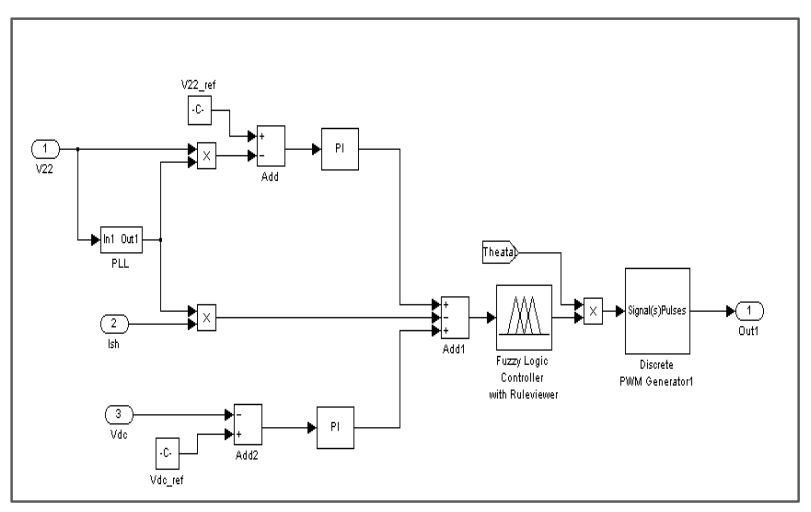

(a)

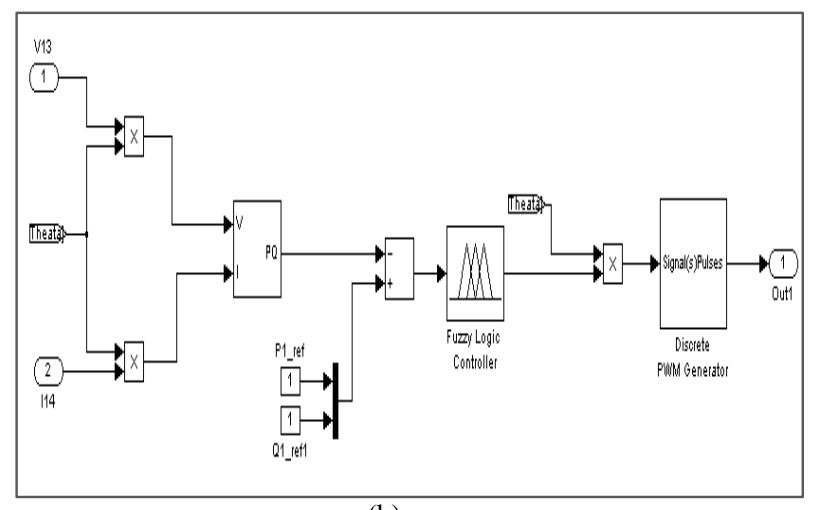

(b)

Figure 5.Control block diagrams of the:

(a) Shunt converter in System 2, (b) Series converter in System 1.

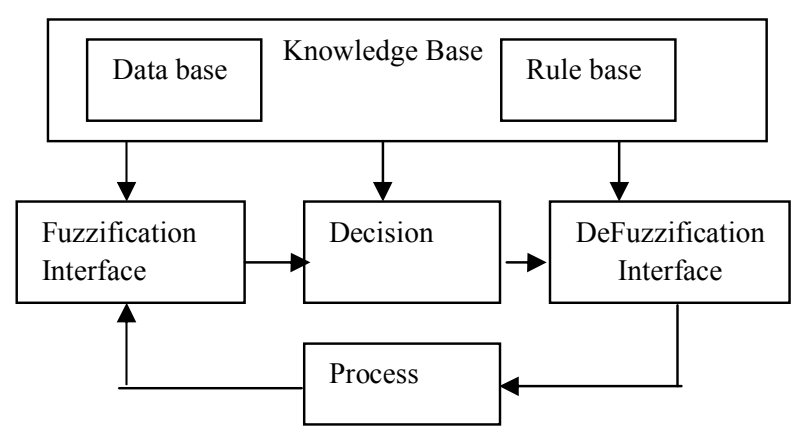

Figure 6.Fuzzy Logic Controller Training of Shunt Fuzzy Controller

\begin{tabular}{|c||c|c|}
\hline$\Delta \mathrm{Ish}(\mathrm{d}, \mathrm{q})(\mathrm{t})$ & $\Delta \mathrm{Ish}(\mathrm{d}, \mathrm{q})(\mathrm{t}-1)$ & $\Delta \mathrm{Vsh}(\mathrm{d}, \mathrm{q})$ \\
\hline 1.58 & 1.02 & 2.22 \\
\hline 2.06 & 1.47 & 2.61 \\
\hline 2.29 & 1.83 & 3.25 \\
\hline 4.10 & 3.04 & 4.42 \\
\hline 4.43 & 3.57 & 5.05 \\
\hline
\end{tabular}

Training of Series Fuzzy Controller

\begin{tabular}{|c|c|c|}
\hline$\Delta \mathrm{P}$ & $\Delta \mathrm{Q}$ & $\mathrm{Vse}(\mathrm{d}, \mathrm{q})$ \\
\hline 1.58 & 1.02 & 2.22 \\
\hline 2.06 & 1.47 & 2.61 \\
\hline 2.29 & 1.83 & 3.25 \\
\hline 4.10 & 3.04 & 4.42 \\
\hline 4.43 & 3.57 & 5.05 \\
\hline
\end{tabular}

The basic configuration of FLC comprises,

i) A Fuzzification which converts input data to linguistic values.

ii) A knowledge base consisting of data base and a linguistic control rule base.

iii) Decision making logic which simulating human thinking infers the fuzzy control action employing fuzzy implication and rules of inference.

iv) A DeFuzzification interface which yields a nonfuzzy control action from an inferred fuzzy control action [2].

\section{INPUT-OUTPUT VARIABLES}

The goal of fuzzy controller is to minimize the oscillations and achieve the steady state response of the system at a faster rate. The replacement of PI controller is shown in Fig 3 and Fig 4.The fuzzy controller uses error (e) and change of error (ce) for linguistic variables.

$$
\begin{aligned}
& e\left(t_{s}\right)=\omega_{s}^{*}\left(t_{s}\right)-\omega_{s}\left(t_{s}\right) \\
& \operatorname{ce}\left(t_{s}\right)=e\left(t_{s}\right)-e\left(t_{s}-1\right)
\end{aligned}
$$




\section{SIMULATION OF MULTILINE POWER SYSTEM WITH IPFC}

The proposed model shows simulation of independent control of two transmission line operating at $11 \mathrm{KV}$ and $33 \mathrm{KV}$ [6]. The compensation model includes the effect of shunt and series converter when there is overloading in the first line. Series and shunt converter are individually represented in the simulated diagram. The combination of series and shunt converter constitute interline power flow controller. Output waveforms are drawn for single phase circuits after including compensation effect with fuzzy controller.

\subsection{Output Waveforms of Single Phase System after Series And Shunt Compensation Using Pi Controller}

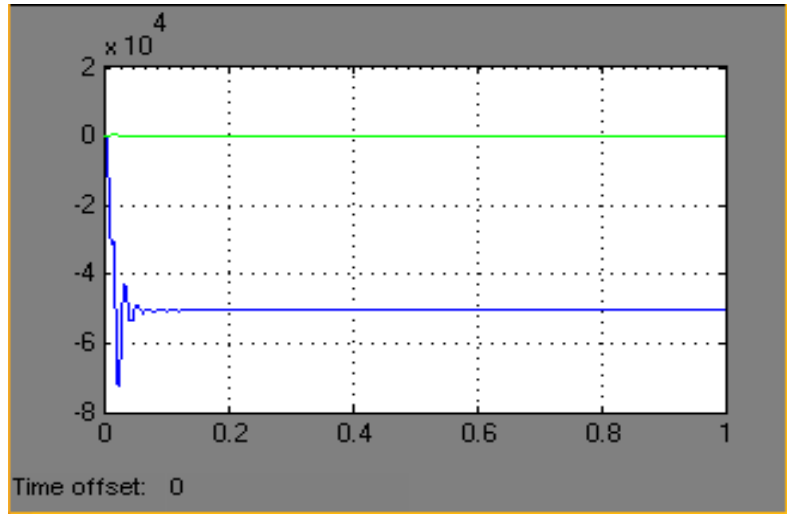

(a)

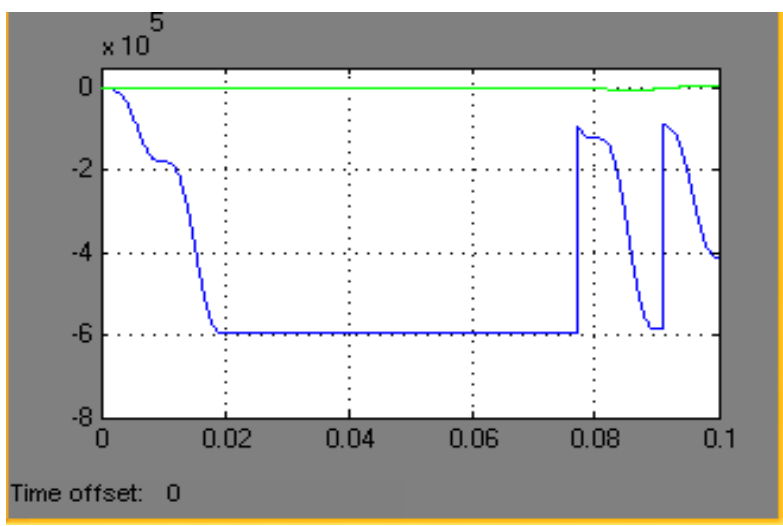

(b)

Figure 7.Output power of line 1

(a)After series compensation, (b) After shunt compensation.

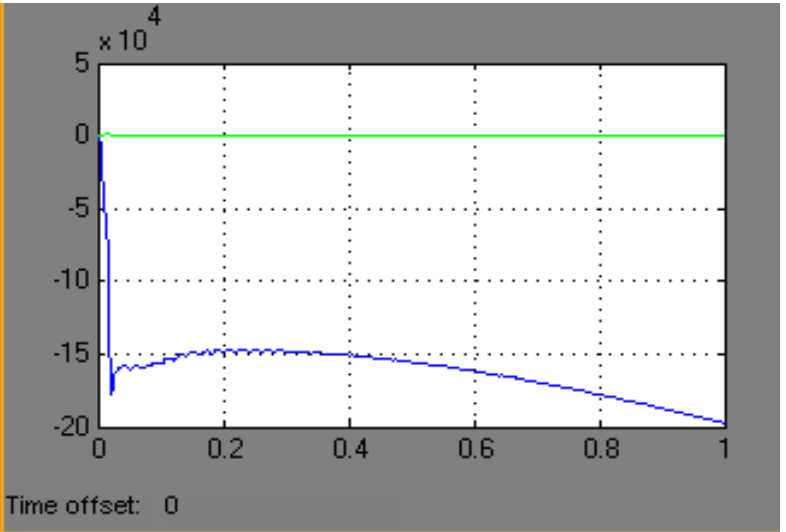

(a)

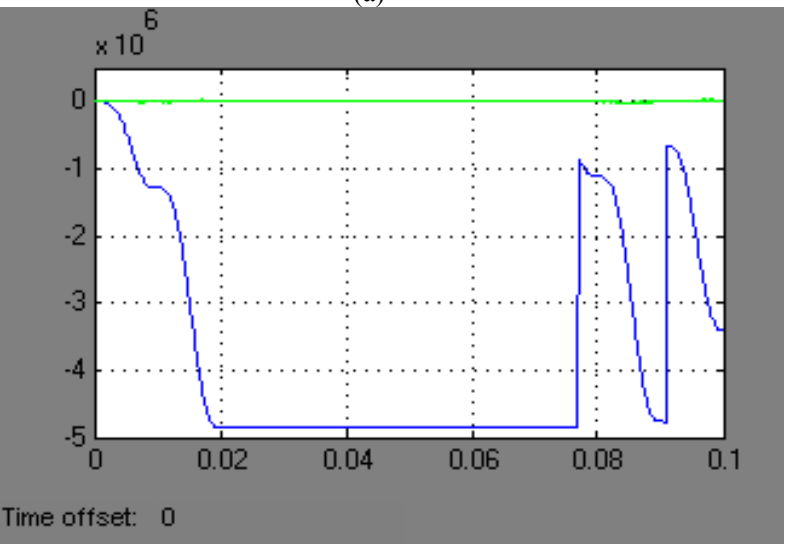

(b)

Figure 8.Output power of line 2

(a) After series compensation, (b) After shunt compensation.

\subsection{Output Waveforms of Single Phase System after Series and Shunt Compensation Using Fuzzy Controller}

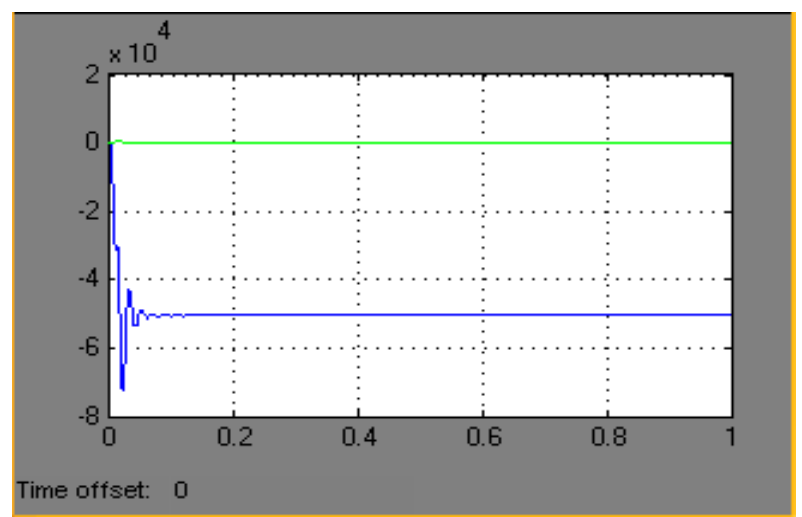

(a) 


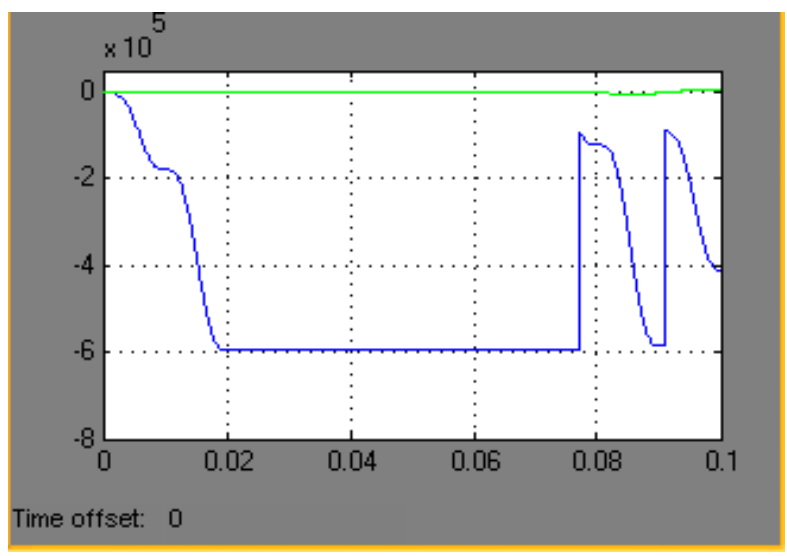

(b)

Figure 9.Output power of line 1

(a) After series compensation, (b) After shunt compensation.

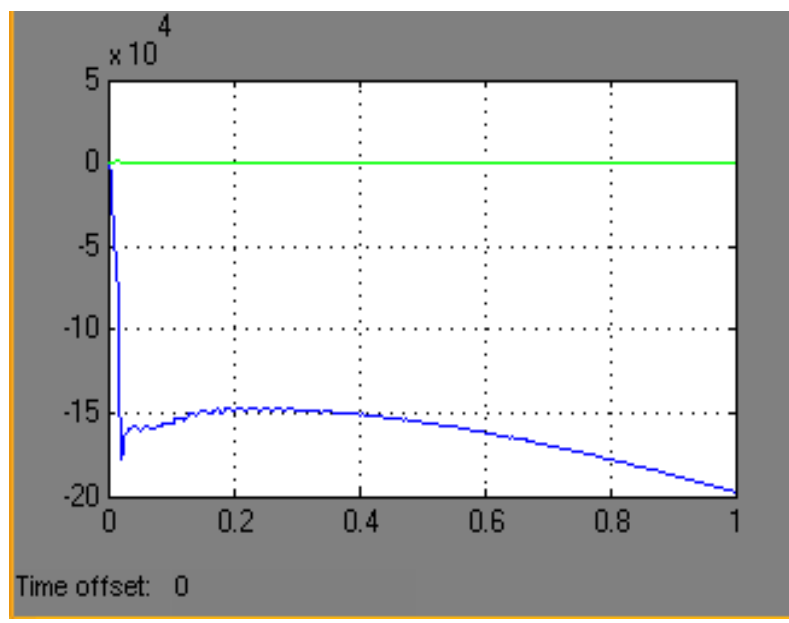

(a)

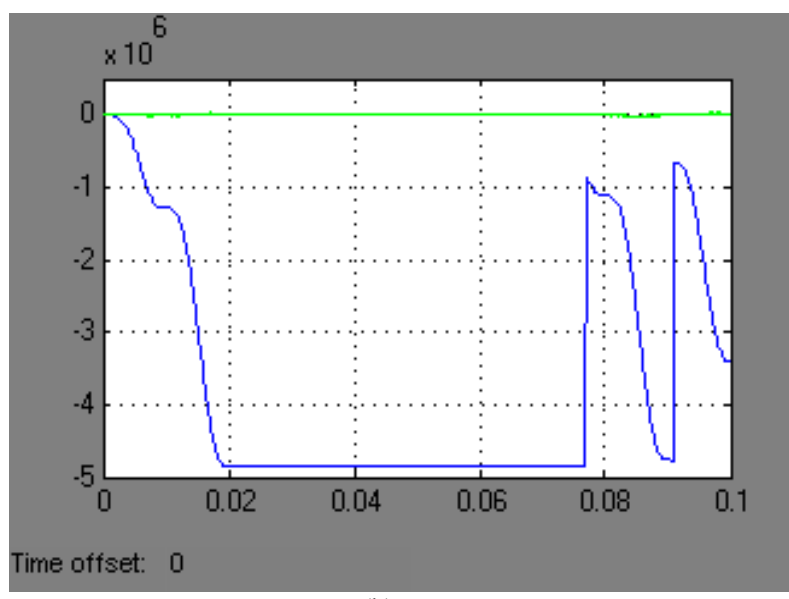

(b)

Figure 10.Output power of line 2

(a) After series compensation. (b) After shunt compensation.

\section{CONCLUSION}

An interline power flow controller is simulated using fuzzy technology and the compensation is provided using series and shunt converters. An independent controllability between multiple transmission lines operating at different $\mathrm{KVs}$ is obtained. The active power and reactive power is measured for both the transmission lines. It is seen from the response that the offset time required for the oscillations to settle down after compensation has reduced when using fuzzy controller instead of PI controller, proving FLC to be more robust for providing compensation.

\section{ACKNOWLEDGMENTS}

We would like to articulate our gratitude to Prof.S.Jaganathan, Department of Electrical and Electronics Engineering for his invaluable suggestions and great encouragement all through this paper work.

Finally we thank our friends Sasi kumar.C and SenthilKumaraVel.K, UG scholars, Department of Electrical and Electronics Engineering for their moral support and invaluable help towards this paper

\section{REFERENECES}

[1] N. G. Hingorani and L. Gyugyi, 2000, "Understanding FACTS: Concepts and Technology of Flexible AC Transmission Systems. Piscataway", NJ: IEEE Press.

[2] B. Lu, L. Hou, B. Li, Y. Liu, 2007, "A New Unified Power Flow Fuzzy Control Method”, Innovative Computing, Information and Control, Second International Conference, pp. $479-489$

[3]Lutfu Saribulut, Mehmet Tumay, and Đlyas Eker, 2007, "Performance Analysis of Fuzzy Logic Based Unified Power Flow Controller" Second International Conference, pp. $500-$ 506.

[4] Timothy J. Ross, 1995, "Fuzzy Logic with engineering application”, McGraw-Hill, Inc.

[5] S. Arabi, P. Kundur, and R. Adapa, Feb. 2000, "Innovative techniques in modelling UPFC for power system analysis," IEEE Trans. Power Syst., vol. 5, no. 1, pp. 336341.

[6] X.Wei, J. H. Chow, B. Fardanesh, and A.-A. Edris, 2004 "A dispatch strategy for an Interline power flow controller operating at rated capacity," in Proc. Power Systems Conf. Expo., New York, Oct. 10-13.

[7] C. Jianhong, T. T. Lie, and D. M. Vilathgamuwa, 2002 "Basic control of Interline power flow controller," in Proc. IEEE Power Eng. Soc., Winter Meeting, vol. 1, pp. 521-525.

[8] R. L. Vasquez-Arnez and L. C. Zanetta Jr., Jun 2005, "Multiline power flow control: An evaluation of the GIPFC (generalized Interline power flow controller)," presented at the 6th Int. Conf. Power Systems Transients, Montreal, QC, Canada, 19-23.

[9] A. Norouzi and A. Sharaf, "Two control schemes to enhance the dynamic performance of the STATCOM \& SSSC," IEEE Trans. on Power Delivery, Vol. 20, Issue 1, pp 435-442, Jan 2005.

[10] V. Diez-Valencia, U. D. Annakkage, A. M. Gole, P. Demchenko, and D. Jocobson, "Interline power Flow Controller concept steady-state operation," IEEE Canadian Conference on Electrical and Computer Engineering, Vol. 1, pp. 280-284, Winnipeg, May 2002. 
[11] J. Chen, T. T. Lie, and D. M. Vilathgamuwa, "Basic control of interline power flow controller," IEEE Power Engineering Society, Vol. 1, pp. 521- 525, Winter 2002.

[12] B. Faradanesh, "Optimal utilization, sizing, and steadystate performance comparison of multi-converter VSC-based FACTS controllers," IEEE Trans. on Power Delivery, Vol. 19, No.3, pp. 1321-1327, July 2004.
[13] N. Hingorani and L. Gyugyi, "Understanding FACTS: Concepts and Technology of Flexible AC Transmission Systems," New York, NY: IEEE Press, 2000.

[14] P.K. Dash, S.Mishra and G.Panda, "Damping Multimodal Power System Oscillation Using a Hybrid Fuzzy Controller for Series Connected Facts Devices", IEEE Transactions on Power Systems, Vol. 15, No. 4, November 2000 . 